\title{
Active case detection of malaria in pregnancy using loop-mediated amplification (LAMP): a pilot outcomes study in South West Ethiopia
}

Guluma Tadesse ${ }^{1}$, Claire Kamaliddinn ${ }^{2,3}$, Cody Doolan ${ }^{2,3}$, Ranmalee Amarasekara ${ }^{2,3}$, Ruth Legese ${ }^{2,3}$, Abu Naser Mohon ${ }^{2,3}$, James Cheaveau ${ }^{2,3}$, Delenasaw Yewhalaw ${ }^{1,4 \dagger}$ and Dylan R. Pillai ${ }^{2,3^{*}+}$

\begin{abstract}
Background: 125 million women are pregnant each year in malaria endemic areas and are, therefore, at risk of Malaria in Pregnancy (MiP). MiP is the direct consequence of Plasmodium infection during pregnancy. The sequestration of Plasmodium falciparum parasites in the placenta adversely affects fetal development and impacts newborn birth weight. Importantly, women presenting with MiP commonly develop anaemia. In Ethiopia, the Ministry of Health recommends screening symptomatic women only at antenatal care visits with no formal intermittent preventive therapy. Since MiP can display low-level parasitaemia, current tests which include microscopy and RDT are challenged to detect these cases. Loop mediated isothermal Amplification (LAMP) technology is a highly sensitive technique for DNA detection and is field compatible. This study aims to evaluate the impact of active malaria case detection during pregnancy using LAMP technology in terms of birth outcomes.

Methods: A longitudinal study was conducted in two health centres of the Kafa zone, South West Ethiopia. Both symptomatic and asymptomatic pregnant women were enrolled in the first or second trimester and allocated to either Standard of Care (SOC - microscopy and RDT) or LAMP (LAMP, microscopy and RDT). Women completed at least three visits prior to delivery, and the patient was referred for treatment if Plasmodium infection was detected by any of the testing methods. The primary outcome was to measure absolute birth weight, proportion of low birth weight, and maternal/neonatal haemoglobin in each arm. Secondary outcomes were to assess the performance of microscopy and RDT versus LAMP conducted in the field.

Results: One hundred and ninety-nine women were included and assigned to either LAMP or SOC. Six were lost to follow up. In this cohort, $66.8 \%$ of women did not display any clinical symptoms and $70.9 \%$ were multi-parous. A reduced proportion of low birth weight newborns was observed in the LAMP group (0\%) compared to standard of care $(14 \%)(p<0.001)$. Improved neonatal haemoglobin was observed in the LAMP $(13.1 \mathrm{~g} / \mathrm{dL})$ versus the SOC $(12.8 \mathrm{~g} /$ $\mathrm{dL})(\mathrm{p}=0.024) \mathrm{arm}$. RDT and microscopy had an analytical sensitivity of $66.7 \%$ and $55.6 \%$ compared to LAMP as a reference standard.
\end{abstract}

\footnotetext{
*Correspondence: drpillai@ucalgary.ca

†Delenasaw Yewhalaw and Dylan R. Pillai co-senior authors

${ }^{2}$ Cumming School of Medicine, Department of Pathology \& Laboratory

Medicine, Diagnostic \& Scientific Centre, The University of Calgary, Room

1W-416, 9-3535 Research Road NW, Calgary, AB T2L 2K8, Canada

Full list of author information is available at the end of the article
}

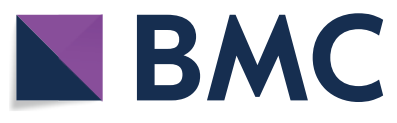

(c) The Author(s) 2020. This article is licensed under a Creative Commons Attribution 4.0 International License, which permits use, sharing, adaptation, distribution and reproduction in any medium or format, as long as you give appropriate credit to the original author(s) and the source, provide a link to the Creative Commons licence, and indicate if changes were made. The images or other third party material in this article are included in the article's Creative Commons licence, unless indicated otherwise in a credit line to the material. If material is not included in the article's Creative Commons licence and your intended use is not permitted by statutory regulation or exceeds the permitted use, you will need to obtain permission directly from the copyright holder. To view a copy of this licence, visit http://creativeco mmons.org/licenses/by/4.0/. The Creative Commons Public Domain Dedication waiver (http://creativecommons.org/publicdomain/ zero/1.0/) applies to the data made available in this article, unless otherwise stated in a credit line to the data. 
Conclusions: These results support the use of highly sensitive tools for rapid on-site active case detection of MiP which may improve birth outcomes in the absence of IPT. However, further large-scale studies are required to confirm this finding.

Keywords: Malaria, Asymptomatic infections, Pregnancy, LAMP, Low birth weight, Anemia, Ethiopia

\section{Background}

Malaria in pregnancy (MiP) is the consequence of Plasmodium infection during pregnancy, and potentially leads to severe disease. MiP results in adverse birth outcomes such as low birth weight (LBW) (defined by a birth weight $<2500 \mathrm{~g})$, small for gestational age fetus $(<10$ th percentile), pre-term birth ( $<37$ weeks of gestational age) and stillbirth. Plasmodium infection and subsequent sequestration of infected erythrocytes in the placenta restricts maternal blood supply, oxygen, and nutrients necessary for normal fetal development [1]. Maternal anaemia is another complication and results from peripheral destruction of infected erythrocytes during Plasmodium asexual multiplication. Nearly 125 million women are pregnant each year in malaria endemic areas and are, therefore, at risk of MiP [2]. In malaria endemic areas, it is estimated that $20 \%$ of stillbirth and $11 \%$ of all newborn deaths are direct consequences of MiP [3]. Both Plasmodium falciparum and Plasmodium vivax induce adverse pregnancy outcomes. Plasmodium falciparum pathogenicity in MiP is well described $[4,5]$ while the pathophysiology of $P$. vivax infection during pregnancy needs yet to be elucidated $[6,7]$.

To prevent the overall clinical and economic burden of MiP, vector protection measures, such as long-lasting insecticide-treated nets are supported. Most countries in sub-Saharan Africa adopt an intermitted preventive treatment (IPT) strategy as per the World Health Organization (WHO) recommendations [8]. IPT consists of mass administration of sulfadoxine-pyrimethamine to pregnant women, starting in the second semester of pregnancy at each antenatal care visit. The use of IPT has demonstrated a positive impact on LBW prevalence and neonatal mortality, by reducing the malaria episodes and the parasitic burden in pregnant women $[9,10]$. However, the use of IPT presents several limitations. First, if the treatment is not administered completely or with poor compliance, IPT contributes to the spread of drug resistant parasites [11, 12]. Second, gametocytes are detected in pregnant women following the administration of IPT [13], which is one of the contributors to malaria transmission. Third, depending on country resources, political stability and strategies for IPT implementation, the coverage of IPT can remain low [14] and IPT implementation may be compromised by medication stock-outs. The WHO estimated that as of 2018, coverage rates for IPT at each antenatal visit were respectively $60 \%, 49 \%$ and $31 \%$ [15]. Fourth, the timing of IPT administration does not allow impact of treatment on early pregnancy infections, which can occur as early as 13 weeks of pregnancy [16]. Early pregnancy infections (before 20 weeks of pregnancy) have an impact on fetal growth and are associated with a lower birth weight at delivery $[17,18]$.

The alternative to IPT strategies is active case detection when women are screened at each antenatal visit for parasite carriage and treated only if Plasmodium spp. are detected. To conduct efficient active case detection, there is a necessity for highly sensitive and affordable point of care (POC) malaria diagnostic tests. Conventional malaria diagnostic methods such as stained blood smear and rapid diagnostic tests (RDT) offer limited sensitivity, with limits of detection (LOD) $>50$ parasites per $\mu \mathrm{L}$. RDT sensitivity is a limitation for MiP active case detection as shown by a clinical trial in Kenya [19]. High sensitive testing with molecular tools such as PCR showed an increase in MiP detection, with 2-2.5-fold more cases detected [20, 21]. Since asymptomatic $P$. falciparum infection during pregnancy is associated with increased maternal anaemia [21], there is a need to evaluate the impact and feasibility of analytically sensitive POC malaria diagnostic. Loop mediated isothermal amplification (LAMP) has excellent analytical sensitivity, can be performed with minimum equipment requirements, and provides a rapid result within $45 \mathrm{~min}[22,23]$. LAMP is one of the isothermal molecular techniques compatible with POC settings. A pilot study was conducted to evaluate active case detection of MiP using LAMP compared to conventional techniques (microscopy and RDT) only. To do so, a prospective outcomes-based study was conducted in two health centres of the Kafa zone, South West Ethiopia.

\section{Methods}

\section{Study population, design, and ethical approvals}

The study was conducted at Gimbo and Gojeb Health Centres, Kafa Zone, SNNP Regional State, Ethiopia. The zone sits at an altitude between 500 and $3500 \mathrm{~m}$ above sea level. Both $P$. vivax and $P$. falciparum are endemic with a seasonal transmission which peaks from September to December. A retrospective study in the Jimma area from September 2007 to August, 2017 showed the prevalence dropping from $27.9 \%$ to $0.62 \%$ between 2007 and 2016 [24]. Pregnant women in their first or second trimester 
of pregnancy attending ANC were included in the study from October 2018 to January 2019. Women presenting with severe malaria symptoms according to WHO guidelines and/or who received anti-malarial drugs in the past four weeks were excluded. Included women were allocated to the standard of care (SOC) arm (1/4) where women were tested by microscopy and RDT, or the LAMP arm (3/4) where women were tested by LAMP, microscopy and RDT (Fig. 1). Women were assigned consecutively between the two study arms during the inclusion visit as they presented in the aforementioned ratio. Women were deemed symptomatic based on self-report of febrile episodes in the past seven days or upon questioning and medical examination at time of enrolment. Women were required to make at least three ANC visits (including enrolment) in addition to the delivery. Testing for haemoglobin and malaria was performed at each visit. Women testing positive for malaria by microscopy/RDT and/or by LAMP technology depending on the study arm were referred to a medical officer for further work up and treatment according to the Federal Ministry of Health guidelines. The study was approved by the research ethics board at Jimma University (IHRPGD/3027/18) and University of Calgary (CHREB 17-1335).

\section{Laboratory and clinical testing at ANC visit}

Women were tested for malaria (described later) and haemoglobin (CareStart biosensor, WellsBio, USA) was measured at each visit. Women with haemoglobin levels lower than $11.0 \mathrm{~g} / \mathrm{dL}$ were considered anaemic. Anaemic patients were subcategorized as mild anaemia (Hb 10.0-10.9 g/dL), moderate anaemia ( $\mathrm{Hb}$ 7.0-9.9 g/dL) and severe anaemia (Hb lower than $7 \mathrm{~g} /$ $\mathrm{dL}$ ) following the WHO recommendation for pregnant women [25]. Whole blood was collected through venous puncture on EDTA anticoagulants tubes. Peripheral blood examination (slides) and RDT (CareStart ${ }^{\mathrm{TM}}$ HRP2/pLDH COMBO (Pf/Pan) detection kits [Accesbio, Korea]) were performed on all samples. Slides (thick and thin films) were air dried, fixed with methanol, and stained with $10 \%$ Giemsa. Slides were read at $100 \times$ oil immersion objective and considered negative after 2000 leucocytes were counted. Microscopy results were made by two independent medical technologists and a third blinded read was performed in case of discrepancy regarding positivity. Parasitaemia per microlitre were estimated using white blood cell (WBC) count or the average of $8000 / \mu \mathrm{L}$ if the WBC count was not available. In the LAMP arm, Plasmodium spp. DNA was additionally detected using a commercial CE-marked LAMP assay (Illumigene,

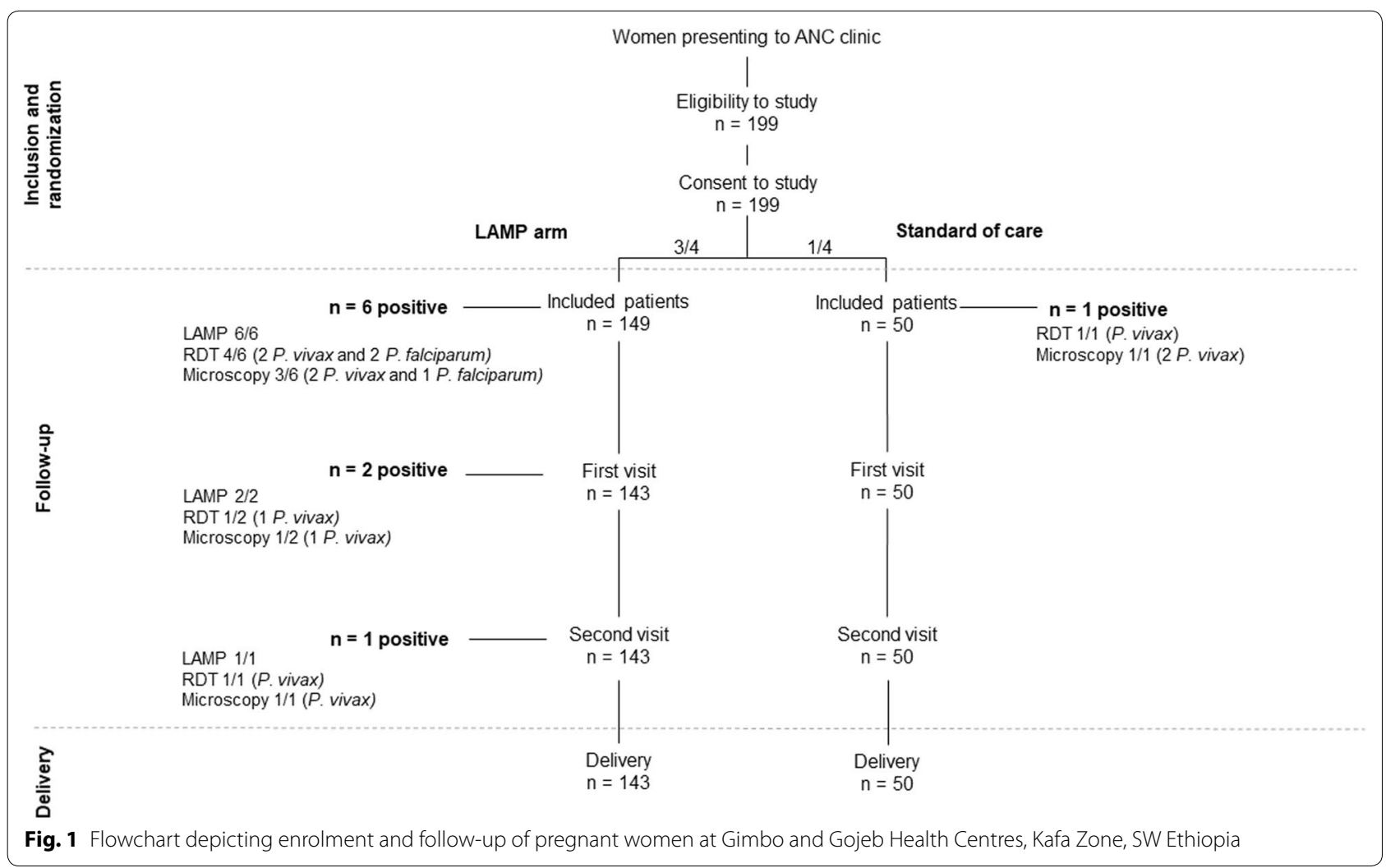


Meridien Bioscience, Cincinnati, $\mathrm{OH}$ ) as per manufacturer's recommendations. Birth outcome and newborn related variables, were performed at the head-to-toes assessment. Fetal haemoglobin was measured using CareStart biosensor (WellsBio, USA) and newborn weight was assessed using standard issue Federal Ministry of Health scales before first feeding.

\section{Statistical analysis}

All statistical analysis were conducted in R software [26]. Graphical outputs were prepared using ggplot2 package [27]. Proportions were compared using Chisquared test and continuous variables with Student's t test or Wilcoxon Mann-Whitney test.

\section{Results}

Demographic data on enrolled patients

One hundred and ninety-nine women were included in the study (99 in Gojeb centre and 100 in Gimbo centre). Women were allocated to the LAMP arm (73 in Gojeb and 76 in Gimbo) or the SOC arm (26 in Gojeb and 24 in Gimbo) using microscopy and/or RDT for malaria diagnosis. Patient characteristics at inclusion are shown in Table 1 and did not differ significantly between the two study arms. Overall, 193 women were followed until delivery (50/50 in the SOC arm and 143/149 in the LAMP arm). Six women (3\%) were lost to follow up due to relocation, delivery at another facility, or logistical challenges.

Malaria prevalence and asymptomatic malaria at inclusion At inclusion, $66.8 \%\left(\mathrm{CI}_{95 \%}\right.$ 59.8-73.3) of women did not display any clinical symptoms. Among women presenting with symptoms, headaches represented $32.7 \%\left(\mathrm{CI}_{95 \%}\right.$ 26.6-39.7), sweating 9.0\% $\left(\mathrm{CI}_{95 \%} 5.6-14.1\right)$ and muscle pain $6.0 \%\left(\mathrm{CI}_{95 \%} 3.3-10.5\right)$ (Fig. 2). Overall, malaria prevalence at diagnosis was $2.0 \%(\mathrm{n}=4 / 200)\left(\mathrm{CI}_{95 \%} 0.7-5.4\right)$ using microscopy/RDT and $4.2 \%(\mathrm{n}=6 / 149)\left(\mathrm{CI}_{95 \%} 1.7-\right.$ 8.9) using LAMP additionally at inclusion. Both $P$. falciparum and $P$. vivax were detected. Average parasitaemia estimated by microscopy was $882.7 \mathrm{p} / \mu \mathrm{L}$ (range 0.94 $1150 \mathrm{p} / \mu \mathrm{L}$ ) at inclusion.

Table 1 Description of the population at inclusion of the study

\begin{tabular}{|c|c|c|c|c|}
\hline Characteristic & All $(n=199)$ & LAMP $(n=149)$ & $\operatorname{SOC}(n=50)$ & $P$ \\
\hline Age, mean (SD), years & $26.4(4.6)$ & $26.2(4.6)$ & $27.1(4.8)$ & 0.224 \\
\hline Haemoglobin, median (IQR), g/dL & $12.00(1.25)$ & $12.00(1.20)$ & $12.01(1.30)$ & 0.698 \\
\hline Parity, no. (\%) & & & & 0.012 \\
\hline Primiparous & $58(29.1)$ & $36(24.2)$ & $22(44.0)$ & \\
\hline Multiparous & $141(70.9)$ & $113(75.8)$ & $28(56.0)$ & \\
\hline Gestational age, mean (SD), weeks & $16.4(5.8)$ & $16.4(5.8)$ & $16.3(5.7)$ & 0.863 \\
\hline Educational level, no. (\%) & & & & 0.794 \\
\hline Illiterate & $78(39.2)$ & $60(40.3)$ & $18(36.0)$ & \\
\hline Read/write & $84(42.2)$ & $64(42.9)$ & $20(40.0)$ & \\
\hline Primary school & $23(11.6)$ & $16(10.7)$ & $7(14.0)$ & \\
\hline Secondary school & $12(6.0)$ & $8(5.4)$ & $4(8.0)$ & \\
\hline College/above & $2(1.0)$ & $1(0.7)$ & $1(2.0)$ & \\
\hline Occupation, no. (\%) & & & & 0.209 \\
\hline Daily labourer & $56(28.1)$ & $37(24.8)$ & $19(38.0)$ & \\
\hline Farmer & $85(42.7)$ & $66(44.3)$ & $19(38.0)$ & \\
\hline Merchant & $18(9.1)$ & $16(10.7)$ & $2(4.0)$ & \\
\hline Housewife & $40(20.1)$ & $30(20.1)$ & $10(20.0)$ & \\
\hline Use of ITN, no. (\%) & & & & 0.897 \\
\hline No usage & $80(40.2)$ & $61(40.9)$ & $19(38.0)$ & \\
\hline Rare & $83(41.7)$ & $62(41.7)$ & $21(42.0)$ & \\
\hline Systematic & $36(18.1)$ & $26(17.4)$ & $10(20.0)$ & \\
\hline Plasmodium spp. prevalence* $\%$ & $4 / 199(2.0)$ & $3 / 149(2.0)$ & $1 / 50(2.0)$ & 0.801 \\
\hline
\end{tabular}

Data are presented for all patients, as well as for each study arm. $P$-values are displayed for comparison between the two arms. Categorical variable were compared using Chi square test and continuous variables using Student's t test

IQR interquartile range, SD standard deviation, ITN insecticide treated nets, LAMP loop mediated amplification, SOC standard of care

* At inclusion, estimation using stained thick blood smear 


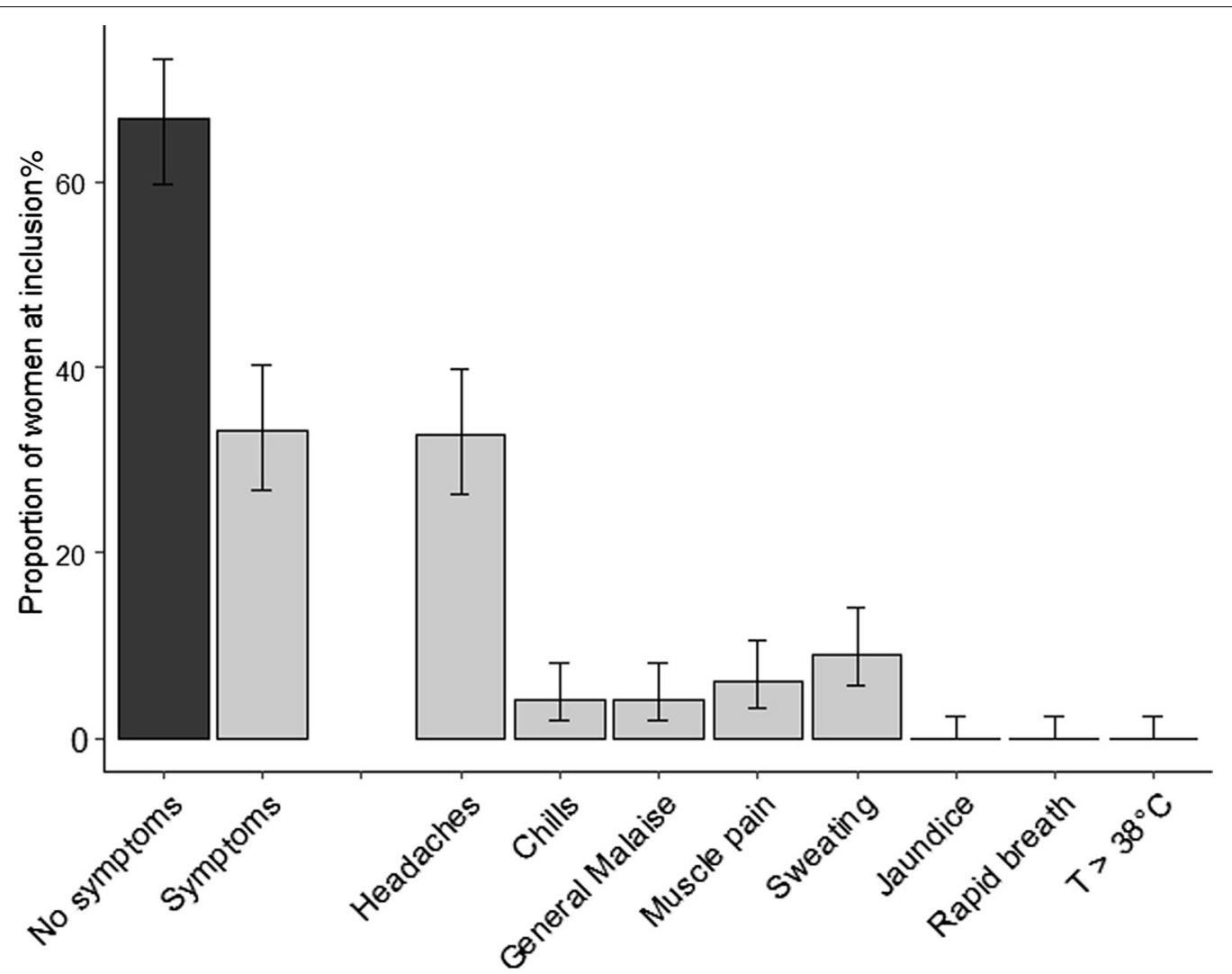

Fig. 2 Characteristics of women at study inclusion $(n=193)$. Bars represent the proportion (\%) of women with corresponding symptoms. Errors bars represent $95 \%$ confidence interval

\section{Malaria during pregnancy and birth weight}

Women were followed up during pregnancy for a total of three visits (including enrolment) during pregnancy and a visit at delivery. In the SOC arm, no additional malaria case was diagnosed during follow-up. In the LAMP arm, $1.4 \%\left(\mathrm{CI}_{95 \%} 0.2-5.4\right)$ were positive at the first visit and $0.7 \%\left(\mathrm{CI}_{95 \%} 0.03-0.4\right)$ at the second follow-up visit. Cumulative prevalence of malaria was $2.0 \%\left(\mathrm{CI}_{95 \%}\right.$ $0.1-1.2)$ in the SOC arm and 6.2\% $\left(\mathrm{CI}_{95 \%} 3.1-11.9\right)$ in the
LAMP arm. At delivery, no adverse major event (preterm deliveries and stillbirth) was noticed in any women (Table 2). Average birth weight was $3.034 \mathrm{~kg}(\mathrm{Q} 1-\mathrm{Q} 3$ [2.750-3.200] kg) for all newborn. Average birth weight was lower in the SOC arm than in the LAMP arm (2.965 vs. $3.059 \mathrm{~kg}$ ) but the difference was not statistically significant $(p=0.148)$. Regarding the proportion of LBW, a significant difference between the standard of care group

Table 2 Birth outcomes related to the study

\begin{tabular}{|c|c|c|c|c|}
\hline Characteristic & All $(n=193)$ & LAMP $(n=143)$ & SOC $(n=50)$ & $p$ \\
\hline Preterm birth (no, \%) & $0(0)$ & $0(0)$ & $0(0)$ & N/A \\
\hline Still birth (no, \%) & $0(0)$ & $0(0)$ & $0(0)$ & N/A \\
\hline Newborn haemoglobin (g/dL) (mean, Q1-Q3) & $13.0[12.7-13.6]$ & $13.1[12.8-13.7]$ & $12.8[12.0-13.4]$ & 0.024 \\
\hline Maternal haemoglobin (g/dL) (mean, Q1-Q3) & $11.5[11.0-12.0]$ & $11.5[11.0-12.0]$ & $11.6[11.0-12.0]$ & 0.771 \\
\hline Low birth weight (no, \%) & $7(3.5)$ & $0(0)$ & $7(14)$ & $<0.001$ \\
\hline Birth weight (kg) (mean, Q1-Q3) & $3.034[2.750-3.200]$ & $3.059[2.761-2.960]$ & $2.965[2.735-3.155]$ & 0.148 \\
\hline
\end{tabular}

Results are presented for all included women and per study arm. Categorical variables were compared using Chi square test and continuous variables using Student's t test

LAMP loop mediated amplification, SOC standard of care 
$(14 \%$ of LBW) and the LAMP group $(0 \%)(p<0.001)$ was observed.

\section{Malaria during pregnancy and anaemia}

Haemoglobin was measured at each ANC visit and at delivery. Anaemia prevalence was $45.6 \%$. Overall, $40.9 \%$ of women presented with mild anaemia and $4.7 \%$ presented with moderate anaemia. These proportions were similar in the LAMP and the SOC arm (45.5\% vs. $46.0 \%)$. The prevalence of anaemia for women positive by LAMP technology was 66.7\% (6/9) (among which 66.7\% (4/6) displayed mild anaemia and $33.3 \%$ (2/6) displayed moderate anaemia). Overall, LAMP positive patients had an average increase of haemoglobin of $0.9 \mathrm{~g} / \mathrm{dL}$ between the initial result and delivery. Improved neonatal haemoglobin was observed in the LAMP $(13.1 \mathrm{~g} / \mathrm{dL})$ versus the $\operatorname{SOC}(12.8 \mathrm{~g} / \mathrm{dL})(\mathrm{p}=0.024)$ arm.

\section{Performance characteristics of RDT and microscopy versus $L A M P$ as a reference method}

The respective sensitivity, specificity, positive predictive value and negative predictive values of RDT, microscopy and LAMP were compared. Microscopy was performed on 585 samples, RDTs on 585 samples and Illumigene LAMP on 435 samples. Analytical performances of RDT and microscopy were evaluated on the 435 samples using LAMP as a reference. Microscopy sensitivity was $55.6 \%$ and specificity $100 \%$ (Table 3 ). RDT sensitivity was $66.7 \%$ and specificity $100 \%$.

\section{Discussion}

A longitudinal study was conducted in the Kafa Zone, Ethiopia and included 199 women at the first or second trimester of pregnancy. Women were allocated to either the standard of care (detection by microscopy/RDT) of Plasmodium spp. infection or to the LAMP arm. The study population was mainly living in rural areas with a limited education level. Use of malaria prophylactic measures such as ITN was low. Overall, the population is representative of the most vulnerable to $\mathrm{MiP}$ and comparable to other recent studies [28, 29]. However, the study population was older (average 26 years) compared to the above mentioned studies (respectively 21 years [29] and 24 years [28]). The retention rate in the study was excellent with only six (3\%) pregnant women lost to follow-up.

Cross-sectional studies in the general population from the same area reported a prevalence of Plasmodium spp. infection from $5.2 \%$ [30] to $11.5 \%$ [31] and even $61.6 \%$ [32]. Golassa et al. evaluated the prevalence at $3.7 \%$ based on microscopy, while the sub-microscopic infection prevalence reached $19.2 \%$ [33]. However, the study population is different from our study which focus on pregnant women during ANC visits. The low prevalence of malaria found in this study may also be related to the low peripheral parasitaemia associated with pregnancy. Importantly, immunity may partially control Plasmodium infection and hence increase the possibility of sub-microscopic parasitaemia during MiP $[4,5,34]$. The higher sensitivity of LAMP compared to RDT and microscopy for MiP was also reported in a cross-sectional study in Colombia [35].

Regarding the prevalence of anaemia, the proportion of women presenting with anaemia was higher in LAMPpositive patients compared to uninfected patients. This

Table 3 Performance of rapid diagnostic tests (RDTs) and microscopy using LAMP as a gold standard ( $\mathrm{n}=435$ samples)

\begin{tabular}{|c|c|c|c|}
\hline \multirow[t]{2}{*}{ LAMP } & \multicolumn{2}{|l|}{ Microscopy } & \multirow[t]{2}{*}{ Total } \\
\hline & Positive & Negative & \\
\hline Positive & 5 & 4 & 9 \\
\hline Negative & 0 & 426 & 426 \\
\hline Total & 5 & 430 & 435 \\
\hline Sensitivity & $55.6 \%$ (95\% Cl 21.10-86.30) & & \\
\hline Specificity & $100.00 \%(95 \%$ Cl 99.14-100.00) & & \\
\hline \multirow[t]{2}{*}{ LAMP } & \multicolumn{2}{|l|}{ RDT } & \multirow[t]{2}{*}{ Total } \\
\hline & Positive & Negative & \\
\hline Positive & 6 & 3 & 9 \\
\hline Negative & 0 & 426 & 426 \\
\hline Total & 6 & 429 & 435 \\
\hline Sensitivity & $66.7 \%(95 \%$ Cl 29.93-92.51) & & \\
\hline Specificity & $100.00 \%$ (95\% Cl 99.14-100.00) & & \\
\hline
\end{tabular}

Data is presented as percentages with $95 \%$ confidence interval 
increase may be a reflection of Plasmodium infection. Importantly, women who tested positive for Plasmodium by LAMP and referred for treatment displayed an increase in maternal and neonatal haemoglobin level at delivery compared to the SOC. Anaemia is, however, multifactorial and nutritional status, deficiencies, and helminths infection are key confounders. For example, a study conducted in 2012 in the Gondar region, Ethiopia, showed that more than half of the study population was positive for soil-transmitted helminths [31].

LBW is an adverse birth outcome associated with MiP that impacts newborn growth and development. A higher proportion of LBW was observed in the SOC arm compared to the LAMP arm. MiP is a key player in fetal growth restriction and subsequent birth outcome [3638]. The absence of LBW in the LAMP arm may reflect the benefits of LAMP testing of asymptomatic MiP and subsequent treatment. This result requires further investigation in a larger cohort with appropriate controls. Both $P$. falciparum and $P$. vivax are endemic in the study zone. RDT performance for $P$. vivax detection is lower than for P. falciparum [39-44]. Plasmodium vivax potential to negatively impact pregnancy has been shown $[45,46]$. Microscopy and RDT showed a low sensitivity compared to LAMP as reported in previous studies [32, 33, 47]. Further study is required to evaluate the impact of ultrasensitive LAMP methods based on RNA detection [48]. Nonetheless, this work shows the superiority of LAMP for MiP diagnosis. However, current commercially available LAMP technology devices and reagents are expensive limiting their use in low and middle-income countries. Endemic malaria areas may greatly benefit from LAMP technology but MiP screening strategies can only be implemented if affordable LAMP test become available.

The results presented here have several limitations. No gold standard (such as PCR or RT-PCR) was used. Also, women were arbitrarily allocated to each arm in a predetermined ratio which may introduce bias. The sample size resulted in a limited number of positive malaria cases limiting the statistical power of the study. Ideally, a comprehensive study for the comparison of IPT and LAMPbased screening of asymptomatic patients would permit a clearer understanding of this strategy. Furthermore, LAMP cannot distinguish active infection from persistent nucleic acid and thus may overcall clinical disease $[40,49,50]$. The study also does not directly address the impact of gametocytaemia as a source of transmission during MiP. In addition, the study design did not permit an analysis of the value of LAMP in symptomatic versus asymptomatic women. Finally, the treatment of patients positive by LAMP was performed outside the study and not directly observed and thus benefits in birth weight and neonatal haemoglobin cannot be necessarily attributed to the LAMP test.

Regarding the practicality of LAMP-based screening for MiP detection, this study shows that the implementation of LAMP is feasible in resource-limited settings. Switching strategies from IPT to screening (LAMP) in settings where IPT is already in place may face additional operational and financial difficulties.

\section{Conclusions}

To summarize, a field study was conducted in the Kafa zone in Ethiopia to assess the impact of LAMP detection of MiP. Interestingly, the LAMP-tested arm showed a lower proportion of LBW and improved newborn hemoglobin levels. Pregnant women and their offspring are likely to benefit from more sensitive tools such as LAMP for MiP detection and subsequent treatment during pregnancy. The findings presented here support further studies using highly sensitive tools for rapid on-site detection of asymptomatic and symptomatic MiP as an alternative to microscopy-based screening or systematic administration of IPT.

\section{Abbreviations \\ ANC: Antenatal care; HRP-2: Histidine rich protein 2; IPT: Intermittent preven- tive treatment; LAMP: Loop mediated isothermal Amplification; LBW: Low birth weight; NPV: Negative predictive value; PCR: Polymerase chain reaction; pLDH: Plasmodium lactate dehydrogenase; POC: Point of care; PPV: Positive predictive value; RDT: Rapid diagnostic test; Se: Sensitivity; Sp: Specificity.}

\section{Acknowledgements}

We thank all the pregnant women who accepted to enroll in the study. We thank the medical staff and midwives from the study centers for their involvement in the study. We thank Meridian Biosciences for providing free kits and instrumentation.

\section{Authors' contributions}

DRP and DY conceived the study, provided resources, financial support. GT, CK, RA, ANM, RL, JC performed technical work, patient enrolment, laboratory studies. All authors read and approved the final manuscript.

\section{Funding}

The work was supported by a grant from Grand Challenges Canada (DRP). We thank Meridian Biosciences for providing free kits and instrumentation.

\section{Availability of data and materials}

The datasets used and/or analysed during the current study are available from the corresponding author on reasonable request.

\section{Ethics approval and consent to participate}

The study protocol was approved by the Institutional Review Board (IRB) of Institute of Jimma University (IHRPGD/3027/18)) and the University of Calgary Conjoint Health Research Ethics Board (REB 17-1335). Permission to conduct the study was obtained from Bonga Zone Health Bureau. Informed consent was obtained from all individuals prior to study participation. Patients diagnosed positive for malaria were treated according to Federal Ministry of Health (Ethiopia) national treatment guidelines.

\section{Consent for publication}

Not applicable. 


\section{Competing interests}

DRP is an Associate Editor of Malaria Journal and Scientific Advisor to Illucidx Inc. that has patents related to LAMP technology. CD is an employee of llucidx Inc.

\section{Author details}

${ }^{1}$ Institute of Health, School of Medical Laboratory Sciences, Jimma University, Jimma, Ethiopia. ${ }^{2}$ Cumming School of Medicine, Department of Pathology \& Laboratory Medicine, Diagnostic \& Scientific Centre, The University of Calgary, Room 1W-416, 9-3535 Research Road NW, Calgary, AB T2L 2K8, Canada. ${ }^{3}$ Cumming School of Medicine, Department of Microbiology, Immunology, and Infectious Diseases, The University of Calgary, Calgary, Canada. ${ }^{4}$ Tropical and Infectious Diseases Research Center, Jimma University, Jimma, Ethiopia.

\section{Received: 22 June 2020 Accepted: 18 August 2020}

Published online: 27 August 2020

\section{References}

1. Ngai M, Weckman AM, Erice C, McDonald CR, Cahill LS, Sled JG, et al. Malaria in pregnancy and adverse birth outcomes: new mechanisms and therapeutic opportunities. Trends Parasitol. 2020;36:127-37.

2. Dellicour S, Tatem AJ, Guerra CA, Snow RW, ter Kuile FO. Quantifying the number of pregnancies at risk of malaria in 2007: a demographic study. PLoS Med. 2010;7:e1000221.

3. Eisele TP, Larsen DA, Anglewicz PA, Keating J, Yukich J, Bennett A, et al. Malaria prevention in pregnancy, birthweight, and neonatal mortality: a meta-analysis of 32 national cross-sectional datasets in Africa. Lancet Infect Dis. 2012;12:942-9.

4. Fried M, Duffy PE. Adherence of Plasmodium falciparum to chondroitin sulfate A in the human placenta. Science. 1996;272:1502-4.

5. Fried M, Duffy PE. Malaria during pregnancy. Cold Spring Harb Perspect Med. 2017;7:a025551.

6. Costa FTM, Lopes SCP, Albrecht L, Ataíde R, Siqueira AM, Souza RM, et al. On the pathogenesis of Plasmodium vivax malaria: perspectives from the Brazilian field. Int J Parasitol. 2012;42:1099-105.

7. Anstey NM, Douglas NM, Poespoprodjo JR, Price RN. Plasmodium vivax: clinical spectrum, risk factors and pathogenesis. Adv Parasitol. 2012;80:151-201.

8. WHO. Guidelines for the treatment of malaria. 3rd Edn. Geneva: World Health Organization; 2015. http://www.who.int/malaria/publications/ atoz/9789241549127/en/. Accessed Nov 182016.

9. Bhutta ZA, Das JK, Bahl R, Lawn JE, Salam RA, Paul VK, et al. Can available interventions end preventable deaths in mothers, newborn babies, and stillbirths, and at what cost? Lancet. 2014;384:347-70.

10. Garner P, Gülmezoglu AM. Drugs for preventing malaria in pregnant women. Cochrane Database Syst Rev. 2006;CD000169.

11. Moussiliou A, De Tove YS-S, Doritchamou J, Luty AJF, Massougbodji A, Alifrangis $M$, et al. High rates of parasite recrudescence following intermittent preventive treatment with sulfadoxine-pyrimethamine during pregnancy in Benin. Malar J. 2013;12:195.

12. Tornyigah B, Coppée R, Houze P, Kusi KA, Adu B, Quakyi I, et al. Effect of drug pressure on promoting the emergence of antimalarial resistant parasites among pregnant women in Ghana. Antimicrob Agents Chemother. 2020;64:e02029-3119.

13. McGready R, White NJ, Nosten F. Parasitological efficacy of antimalarials in the treatment and prevention of falciparum malaria in pregnancy 1998 to 2009: a systematic review. Int J Obstet Gynaecol. 2011;118:123-35.

14. Roman E, Andrejko K, Wolf K, Henry M, Youll S, Florey L, et al. Determinants of uptake of intermittent preventive treatment during pregnancy: a review. Malar J. 2019;18:372.

15. WHO. World Malaria Report Geneva: World Health Organization; 2019 https://www.who.int/publications/i/item/world-malaria-report-2019.

16. Doritchamou J, Bertin G, Moussiliou A, Bigey P, Viwami F, Ezinmegnon S, et al. First-trimester Plasmodium falciparum infections display a typical "placental" phenotype. J Infect Dis. 2012;206:1911-9.

17. Cottrell G, Mary J-Y, Barro D, Cot M. The importance of the period of malarial infection during pregnancy on birth weight in tropical Africa. Am J Trop Med Hyg. 2007;76:849-54.
18. Huynh B-T, Cottrell G, Cot M, Briand V. Burden of malaria in early pregnancy: a neglected problem? Clin Infect Dis. 2015;60:598-604.

19. Desai M, Gutman J, Llanziva A, Otieno K, Juma E, Kariuki S, et al. Intermittent screening and treatment or intermittent preventive treatment with dihydroartemisinin-piperaquine versus intermittent preventive treatment with sulfadoxine-pyrimethamine for the control of malaria during pregnancy in western Kenya: an open-label, three-group, randomised controlled superiority trial. Lancet. 2015;386:2507-19.

20. Unger HW, Rosanas-Urgell A, Robinson LJ, Ome-Kaius M, Jally S, Umbers AJ, et al. Microscopic and submicroscopic Plasmodium falciparum infection, maternal anaemia and adverse pregnancy outcomes in Papua New Guinea: a cohort study. Malar J. 2019;18:302.

21. Cottrell G, Moussiliou A, Luty AJF, Cot M, Fievet N, Massougbodji A, et al. Submicroscopic Plasmodium falciparum infections are associated with maternal anemia, premature births, and low birth weight. Clin Infect Dis. 2015;60:1481-8.

22. Lucchi NW, Gaye M, Diallo MA, Goldman IF, Ljolje D, Deme AB, et al. Evaluation of the Illumigene malaria LAMP: a robust molecular diagnostic tool for malaria parasites. Sci Rep. 2016;6:36808.

23. Parida M, Sannarangaiah S, Dash PK, Rao PVL, Morita K. Loop mediated isothermal amplification (LAMP): a new generation of innovative gene amplification technique; perspectives in clinical diagnosis of infectious diseases. Rev Med Virol. 2008;18:407-21.

24. Jemal A, Ketema T. A declining pattern of malaria prevalence in Asendabo Health Center Jimma zone, Southwest Ethiopia. BMC Research Notes. 2019;12:290.

25. WHO. Haemoglobin concentrations for the diagnosis of anaemia and assessment of severity. 2007 p. 6. Report No.: WHO/NMH/NHD/ MNM/11.1. https://www.who.int/vmnis/indicators/haemoglobin.pdf.

26. R Core Team. R: A language and environment for statistical computing. Vienna: R Foundation for Statistical Computing; 2017. https://www.Rproject.org/.

27. Wickham H. ggplot2: Elegant graphics for data analysis. New York: Springer-Verlag; 2009. https://www.springer.com/gp/book/9780387981 413. Accessed Dec 172019.

28. Briggs J, Ategeka J, Kajubi R, Ochieng T, Kakuru A, Ssemanda C, et al. Impact of microscopic and submicroscopic parasitemia during pregnancy on placental malaria in a high-transmission setting in Uganda. J Infect Dis. 2019;220:457-66.

29. Tuikue Ndam N, Tornyigah B, Dossou AY, Escriou G, Nielsen MA, Salanti A, et al. Persistent Plasmodium falciparum infection in women with an intent to become pregnant as a risk factor for pregnancy-associated malaria. Clin Infect Dis. 2018;67:1890-6.

30. Alemu A, Tsegaye W, Golassa L, Abebe G. Urban malaria and associated risk factors in Jimma town, south-west Ethiopia. Malar J. 2011;10:173.

31. Alemu A, Shiferaw $Y$, Ambachew A, Hamid H. Malaria helminth coinfections and their contribution for aneamia in febrile patients attending Azzezo health center, Gondar, Northwest Ethiopia: a cross sectional study. Asian Pac J Trop Med. 2012:5:803-9.

32. Alemu A, Fuehrer H-P, Getnet G, Kassu A, Getie S, Noedl H. Comparison of Giemsa microscopy with nested PCR for the diagnosis of malaria in North Gondar, north-west Ethiopia. Malar J. 2014;13:174.

33. Golassa L, Enweji N, Erko B, Aseffa A, Swedberg G. Detection of a substantial number of sub-microscopic Plasmodium falciparum infections by polymerase chain reaction: a potential threat to malaria control and diagnosis in Ethiopia. Malar J. 2013;12:352.

34. Fried M, Nosten F, Brockman A, Brabin BJ, Duffy PE. Maternal antibodies block malaria. Nature. 1998:395:851-2.

35. Vásquez AM, Zuluaga L, Tobón A, Posada M, Vélez G, González IJ, et al. Diagnostic accuracy of loop-mediated isothermal amplification (LAMP) for screening malaria in peripheral and placental blood samples from pregnant women in Colombia. Malar J. 2018;17:262.

36. Accrombessi M, Yovo E, Cottrell G, Agbota G, Gartner A, Martin-Prevel Y, et al. Cohort profile: effect of malaria in early pregnancy on fetal growth in Benin (RECIPAL preconceptional cohort). BMJ Open. 2018;8:e019014.

37. Accrombessi M, Zeitlin J, Massougbodji A, Cot M, Briand V. What do we know about risk factors for fetal growth restriction in Africa at the time of sustainable development goals? A scoping review. Paediatr Perinat Epidemiol. 2018;32:184-96.

38. Guyatt HL, Snow RW. Impact of malaria during pregnancy on low birth weight in sub-Saharan Africa. Clin Microbiol Rev. 2004;17:760-9. 
39. Houzé S, Boutron I, Marmorat A, Dalichampt M, Choquet C, Poilane I, et al. Performance of rapid diagnostic tests for imported malaria in clinical practice: results of a national multicenter study. PLoS ONE. 2013;8:e75486.

40. Kamaliddin C, Le Bouar M, Berry A, Fenneteau O, Gillet P, Godineau N, et al. Assessment of diagnostic methods for imported malaria in mainland France. Med Mal Infect. 2019;50:141-60.

41. Gillet P, van Dijk DPJ, Bottieau E, Cnops L, Van Esbroeck M, Jacobs J. Test characteristics of the SD FK80 Plasmodium falciparum/Plasmodium vivax malaria rapid diagnostic test in a non-endemic setting. Malar J. 2009;8:262.

42. Gillet P, Bosselaers K, Cnops L, Bottieau E, Van Esbroeck M, Jacobs J. Evaluation of the SD FK70 malaria Ag Plasmodium vivax rapid diagnostic test in a non-endemic setting. Malar J. 2009;8:129.

43. Heutmekers M, Gillet P, Maltha J, Scheirlinck A, Cnops L, Bottieau E, et al. Evaluation of the rapid diagnostic test CareStart pLDH Malaria (Pf-pLDH) pan-pLDH) for the diagnosis of malaria in a reference setting. Malar J. 2012;11:204.

44. Larréché S, Rapp C, Delacour H, Sanmartin N, Ficko C, Bigaillon C, et al. Sensitivity of parasitological tests in imported Plasmodium vivax malaria in adults and impact of chemoprophylaxis and attack type. J Travel Med. 2014;21:195-200.

45. Bardají A, Martínez-Espinosa FE, Arévalo-Herrera M, Padilla N, Kochar S, Ome-Kaius $M$, et al. Burden and impact of Plasmodium vivax in pregnancy: a multi-centre prospective observational study. PLoS Negl Trop Dis. 2017;11:e0005606.
46. Datta M, Biswas J, Dasgupta S, Banerjee K, Choudhury S, Sengupta SK, et al. Comparative study on antenatal and perinatal outcome of vivax and falciparum malaria in a tertiary care hospital of Kolkata, India. J Clin Diagn Res. 2017;11:QC01-4.

47. Pöschl B, Waneesorn J, Thekisoe $O$, Chutipongvivate S, Karanis P, Panagiotis K. Comparative diagnosis of malaria infections by microscopy, nested PCR, and LAMP in northern Thailand. Am J Trop Med Hyg. 2010;83:56-60.

48. Mohon AN, Getie S, Jahan N, Alam MS, Pillai DR. Ultrasensitive loop mediated isothermal amplification (US-LAMP) to detect malaria for elimination. Malar J. 2019;18:350.

49. Iqbal J, Siddique A, Jameel M, Hira PR. Persistent histidine-rich protein 2, parasite lactate dehydrogenase, and panmalarial antigen reactivity after clearance of Plasmodium falciparum monoinfection. J Clin Microbiol. 2004;42:4237-41.

50. Aydin-Schmidt B, Mubi M, Morris U, Petzold M, Ngasala BE, Premji Z, et al. Usefulness of Plasmodium falciparum-specific rapid diagnostic tests for assessment of parasite clearance and detection of recurrent infections after artemisinin-based combination therapy. Malar J. 2013;12:349.

\section{Publisher's Note}

Springer Nature remains neutral with regard to jurisdictional claims in published maps and institutional affiliations.
Ready to submit your research? Choose BMC and benefit from:

- fast, convenient online submission

- thorough peer review by experienced researchers in your field

- rapid publication on acceptance

- support for research data, including large and complex data types

- gold Open Access which fosters wider collaboration and increased citations

- maximum visibility for your research: over 100M website views per year

At BMC, research is always in progress.

Learn more biomedcentral.com/submissions 